\title{
Vormgeven van patiëntveiligheidsonderwijs: een integraal onderdeel van verantwoorde zorg
}

\author{
Lisanne M. Verweij ${ }^{1}$ Martine C. de Bruijne ${ }^{2} \cdot$ A. Heleen de Vries ${ }^{3} \cdot$ Cordula Wagner $^{2}$
}

Published online: 9 November 2016

(C) The Author(s) 2016. This article is available at SpringerLink with Open Access.

Samenvatting De moderne gezondheidszorg is een complex systeem, dat voortdurend verandert als gevolg van nieuwe technologische en organisatorische ontwikkelingen. Patiëntveiligheid staat daarbij hoog in het vaandel. Toch komt patiëntveiligheid soms (onbewust) in het gedrang, waardoor medische fouten kunnen ontstaan met schade voor de patiënt tot gevolg.

Onderwijs op het gebied van patiëntveiligheid vindt meestal slechts impliciet plaats in de specialistische opleiding en gebeurt weinig op het niveau van het basiscurriculum voor studenten en de vervolgopleiding voor aios. Een goed curriculum legt de basis voor een leven lang leren en het waarborgen van patiëntveiligheid gedurende de hele loopbaan. Met een betere inbedding van patiëntveiligheidsonderwijs in curriculae kan een generatie artsen worden opgeleid die een bewustere houding ten aanzien van patiëntveiligheid behoudt, te midden van de uitdagingen van een constant veranderende, complexe werkomgeving.

Het eerste deel van deze bijdrage gaat in op patiëntveiligheid als integraal onderdeel van verantwoorde zorg; het tweede deel op het vormgeven van patiëntveiligheidsonderwijs.

Trefwoorden patiëntveiligheid $\cdot$ onderwijs $\cdot$ levenslang leren

dr. Lisanne M. Verweij

1.verweij@nivel.nl

1 NIVEL, Utrecht, Nederland

2 Vrije Universiteit medisch centrum/EMGO+Instituut, Amsterdam, Nederland

3 aios urologie, Zaans Medisch Centrum, Zaandam, Nederland
Embedding patient safety education in medical curricula: an integral part of ensuring responsible care

Abstract Modern health care is a complex and constantly changing system, due to technological and organisational advances. Patient safety has a central role in many organisations. However, it can (unconsciously) be threatened, leading to adverse events. Patient safety education is primarily provided merely and only implicitly, to residents and is incorporated too little in the student curriculum. A good curriculum fits the concept of life-long learning and ensures attention for patient safety throughout careers. Embedding patient safety education in medical curricula will lead to a generation of doctors that is more aware of patient safety issues, amidst the challenges of the constant changing and complex work environment.

Keywords patient safety $\cdot$ education $\cdot$ life long learning

\section{Patiëntveiligheid: een integraal onderdeel van verantwoorde zorg}

Patiëntveiligheid is het (nagenoeg) ontbreken van (de kans op) schade aan een patiënt, veroorzaakt door niet volgens de professionele standaard handelen van de zorgverlener en/of door tekortkomingen in het zorgsysteem [1]. Patiëntveiligheid gaat over het voorkómen van zorggerelateerde schade aan de patiënt. "Ik zal aan de patiënt geen schade doen" staat er in de Artseneed van de KNMG en de VSNU van 2003. Hoewel er zelden sprake is van het opzettelijk schaden van patiënten, komt schade gerelateerd aan geleverde zorg voor. Landelijk onderzoek in 2011/2012 heeft laten zien dat $7,1 \%$ van de in het ziekenhuis opgenomen 
patiënten zorggerelateerde schade met tijdelijke of blijvende gevolgen oploopt [2]. Bij 1,6\% van alle ziekenhuisopnamen lopen patiënten vermijdbare zorggerelateerde schade op. Jaarlijks overlijden naar schatting 970 patiënten in het ziekenhuis, mede ten gevolge van vermijdbare zorggerelateerde schade.

De moderne gezondheidszorg is een complex systeem, dat voortdurend verandert door nieuwe technologische en organisatorische ontwikkelingen. Door specialisatie en taaksubstitutie, kortere werktijden en toenemende efficiëntie van de zorg, wordt zorg steeds meer door verschillende professionals geleverd, die veelvuldig informatie moeten overdragen en in steeds wisselende teams samenwerken [3]. Het is niet eenvoudig om zorggerelateerde schade te vermijden in een dergelijke complexe organisatie van de gezondheidszorg, waarbinnen sterk gespecialiseerde professionals samen zorg verlenen. Normale menselijke beperkingen rond informatieopname en -verwerking, miscommunicatie, onvoldoende (goed opgeleid) personeel en problemen rond apparatuur zijn veelvoorkomende oorzaken van het ontstaan van zorggerelateerde schade [2]. Van artsen wordt daarom verlangd verantwoordelijkheid te nemen ten aanzien van patiëntveiligheid, bijvoorbeeld door verstandig om te gaan met vermoeidheid en andere risico's. Kun je nog opereren na een lange zware nachtdienst? Kan een vernieuwd apparaat gebruikt worden zonder voldoende instructie? Het maken van dergelijke afwegingen is lang niet altijd makkelijk. Patiëntveiligheid komt soms (onbewust) in het gedrang, waardoor medische fouten kunnen ontstaan, waarvan de patiënt schade lijdt.

Een proactieve houding ten aanzien van patiëntveiligheid, zowel van de professional als de zorgorganisatie, is noodzakelijk om patiëntveiligheid te verbeteren en te borgen. Patiëntveiligheid, als integraal onderdeel van verantwoorde zorg, dient daarom ook integraal in de artsenopleiding ingebed te zijn [4].

In Nederland worden in het raamplan voor de artsenopleiding 2009, naast medisch handelen, zes andere competenties benoemd die centraal staan in de opleiding, waaronder communicatie, samenwerking, organisatie en professionaliteit [5]. Het raamplan stelt dat de juist afgestudeerde arts kennis van en inzicht in aspecten van kwaliteit van zorg en patiëntveiligheid heeft. In de praktijk is het onderwijs over samenwerken met andere professionals en patiëntveiligheid echter nog niet altijd systematisch uitgewerkt en ingevoerd in het onderwijs [6]. Onderwijs om kennis, vaardigheden en gedrag ten aanzien van patiëntveiligheid te verbeteren, dienen duidelijk herkenbaar opgenomen te zijn in curricula en regelmatig terug te keren, bij voorkeur geïntegreerd in ander medisch onderwijs. Onderwijs op het gebied van patiëntveiligheid vindt nu vooral impliciet plaats in de specialistische opleiding, beperkt zich veelal tot onderdelen van patiëntveiligheid, zoals systeemdenken of menselijke factoren, of gebeurt ad hoc in diverse blokken van onderwijs. Dit maakt dat er in het onderwijs onvoldoende aandacht uitgaat naar specifieke randvoorwaarden van patiëntveiligheid, zoals een open cultuur waarin geleerd kan worden van fouten, openheid over fouten naar de patiënt, analyse van oorzaken bij medische fouten, de zorgverlener als second victim en het belang van peer-topeer support, en de rol van niet-technische vaardigheden, zoals optimale intercollegiale communicatie en klinisch leiderschap [6]. De basis voor competenties ten aanzien van patiëntveiligheid kan het best worden gelegd in het basiscurriculum voor studenten en de vervolgopleiding voor aios, waarbij competenties naar de mate van ervaring worden opgebouwd. De basisopleiding heeft als doel risico's voor patiëntveiligheid te kennen en te herkennen, wat zich in de vervolgopleiding verder ontwikkelt naar het herkennen van risico's voor de patiëntveiligheid in de dagelijkse praktijk en het toepassen van niet-technische vaardigheden. Een goed curriculum legt de basis voor leven lang leren en het waarborgen van patiëntveiligheid gedurende de hele loopbaan [6].

\section{Patiëntveiligheid binnen de urologie}

Binnen de urologie is patiëntveiligheid een belangrijk onderwerp binnen het onderwijs. Urologen hebben te maken met acute en chronische patiënten, met kwetsbare ouderen, maar ook met kinderen en zij zijn betrokken bij het gehele proces, van diagnostiek tot interventie en follow-up. Een lange cascade, waarbij patiëntveiligheid bij iedere stap in het gedrang zou kunnen komen. De laatste jaren zijn binnen de urologie daarom flinke stappen gezet om het onderwijs van de vervolgopleiding te moderniseren en naar een hoger niveau te tillen [4]. Zo werd in september 2014 het Urologisch Vaardigheid Onderwijs (UVO) geïntroduceerd. Een van de doelen van UVO is om de patiëntgerelateerde leercurve van basisurologische vaardigheden te verkorten, door deze in een risicovrije simulatieomgeving te trainen. Daarmee zijn eerste stappen gezet naar integrale inbedding van patiëntveiligheid in de artsenopleiding. Het UVO betreft modulair, niet patiëntgebonden vaardigheidsonderwijs, waarin aios hun technische en niet-technische basisurologische vaardigheden trainen. Het onderwijs vindt plaats in kleine groepjes in de lokale ziekenhuissetting, waarbij getraind wordt op simulatiemodellen. De modules worden begeleid door urologen en ook peer teaching wordt ingezet. Op dezelfde wijze werkt de UVO-vervolgopleiding toe naar het herkennen van risico's voor de patiëntveiligheid in de dagelijkse praktijk en toepassen van niet-technische vaardigheden. De implementatie van het UVO zou uiteindelijk moeten leiden tot een verbeterde patiëntveiligheid en kwaliteit van zorg [7]. 


\section{Vormgeven van patiëntveiligheidsonderwijs}

Het belangrijkste doel van patiëntveiligheidsonderwijs is dat studenten en aios patiëntveiligheidsaspecten in de praktijk herkennen, dat ze deze aspecten kunnen benoemen en dat ze anderen hierop kunnen aanspreken. Patiëntveiligheid maakt ook onderdeel uit van de navolgende competenties van beroepsbeoefenaars [8]:

- medische fouten te (h)erkennen en te melden bij de daarvoor bestemde instanties.

- adequaat om te gaan met fouten van zichzelf of van anderen, eigen fouten tegenover patiënten en collega's te erkennen en er lering uit te trekken.

Bij het bepalen van het beheersingsniveau van competenties dient rekening gehouden te worden met de verantwoordelijkheden die een student of aios in zijn opleiding heeft. Om deze reden worden (voor de uroloog eveneens) belangrijke onderwerpen, zoals het nemen van afdelingsverantwoordelijkheid, het leggen van een relatie tussen patiëntveiligheid en processen in de organisatie, en het organiseren van essentiële processen in het kader van patiëntveiligheid, niet opgenomen in de opleiding. Maar deze onderwerpen zijn wel van belang voor onderwijs aan specialisten.

Er zijn drie frameworks die kunnen dienen als basis voor patiëntveiligheidsonderwijs:

- de WHO Patient Safety Curriculum Guide for Medical School uit 2009 [9];

- de CanMEDS-systematiek voor het beschrijven van de verschillende rollen (competenties) van zorgprofessionals (2015) [10];

- de VMS Nederlandse discipline-overstijgende veiligheidscompetenties uit 2013 [1].

Het CanMEDS framework en ook de Nederlandse VMSveiligheidscompetenties vatten patiëntveiligheid op hoofdlijnen samen. Om het onderwijs rond patiëntveiligheid vorm te geven, kan voor de praktijk goed worden uitgegaan van de 11 onderwerpen die worden voorgesteld in de WHO Patient Safety Curriculum Guide for Medical School [9]. Deze onderwerpen illustreren tevens wat patiëntveiligheidsonderwijs in praktische zin omvat

1. Wat is patiëntveiligheid?

Het begrip patiëntveiligheid wordt geïntroduceerd. Studenten en aios leren de omvang, oorzaken en gevolgen van patiëntonveiligheid en op welke wijze zorggerelateerde schade kan worden beperkt.

2. Menselijke factoren en de impact op patiëntveiligheid Menselijke factoren zijn bijvoorbeeld vermoeidheid of het (onbewust) niet goed opnemen of verwerken van informatie. Systemen en producten kunnen helpen bij het beter uitvoeren van taken. Studenten en aios leren hoe menselijke factoren bijdragen aan het ontstaan van zorggerelateerde schade en hoe deze schade voorkomen kan worden.

3. Systeemdenken en de invloed van complexiteit op patiëntenzorg

De gezondheidszorg bestaat uit een complex geheel van organisaties, afdelingen, verpleegeenheden, etc. Voor het analyseren van oorzaken van patiëntveiligheidsincidenten is het belangrijk om daar niet alleen de persoon die het incident veroorzaakte, maar ook de organisatie, het proces, de technische middelen en de patiënt bij te betrekken.

4. Een effectieve teamspeler zijn

Samenwerken is aan de orde van de dag in de medische praktijk en kan een bron zijn van risicovolle situaties. Door de capaciteiten in een team van samenwerkende professionals optimaal te benutten, kan patiëntveiligheid aanzienlijk worden vergroot. Hiervoor zijn, naast medische kennis en vaardigheden, ook competenties zoals communicatie, mens- en taakgericht leiderschap en adequate besluitvorming van belang. Studenten en aios horen te weten hoe ze een effectief lid van een team kunnen zijn. Het gaat hierbij ook om begrip van de cultuur en hoe iemands cultuur invloed heeft op het functioneren in een team.

5. Fouten begrijpen en er van leren

Belangrijk bij dit leerdoel is dat studenten en aios begrijpen dat het beter is om te begrijpen welke factoren ten grondslag liggen aan een fout, dan dat men mensen als schuldigen aanwijst.

6. Klinische risico's begrijpen en managen

Klinisch risicomanagement richt zich op het verbeteren van kwaliteit en patiëntveiligheid door na te gaan onder welke omstandigheden en gelegenheden patiënten risico lopen. Risicomanagement gaat dan in op het voorkómen of beter controleren van deze risico's. Bij dit onderwerp gaat het ook om klachtenregelingen.

7. Methoden om kwaliteit te verbeteren introduceren Het gaat hierbij om vergaren van kennis over methoden die studenten en aios in staat stellen om: 1) het probleem te benoemen, 2) het probleem te meten, 3 ) interventies te bedenken om het probleem op te lossen en 4) te testen of de interventies hebben gewerkt.

8. Omgaan met patiënten en mantelzorgers

Studenten en aios leren hierbij dat patiënten en hun mantelzorgers (mits goed geïnformeerd) een belangrijke rol kunnen spelen bij veilige gezondheidszorg. Ze vormen een tweede paar ogen als iets onverwachts gebeurt.

9. Infecties minimaliseren door verbeterde controle Iatrogene infecties zijn een belangrijke oorzaak van sterfte en ziekte bij patiënten. Bij dit onderwerp doen studenten en aios kennis op over de belangrijkste typen 
en oorzaken van infecties, waarbij studenten en aios begrijpen welke activiteiten risicovol zijn voor patiënten en hoe zij dienen te handelen om transmissie te voorkomen.

\section{Patiëntveiligheid bij invasieve procedures}

De WHO richt zich op operaties, maar binnen ons onderwijs wordt dit verbreed naar patiëntveiligheid bij medische handelingen, zoals infuus prikken, venapunctie etc. Het gaat hierbij om het belang van beleid, protocollen en procedures.

11. Medicatieveiligheid

Patiënten zijn kwetsbaar voor fouten die zijn gemaakt bij het bestellen, verstrekken en toedienen van medicijnen. Studenten en aios leren hoe ze veilig met medicatie om kunnen gaan

Met integratie in het bestaande onderwijs kan voorkomen worden dat studenten en aios het gevoel krijgen overladen te worden met patiëntveiligheidsonderwijs. Dat zal een precair evenwicht zijn: wanneer patiëntveiligheid te vaak en/of te oppervlakkig wordt aangestipt, ervaren studenten en aios dat ze het al hebben gehad.

Pas in de kliniek wordt patiëntveiligheid vaak echt iets tastbaars. Door patiëntveiligheidsonderwijs te richten op de thema's en actuele casus waarbij de patiëntveiligheid in het gedrang kan komen, wordt een eerste stap naar bewustwording gezet. Daarbij is het relevant om vooral gebruik te maken van de casuïstiek die studenten en aios zelf meemaken, om zo aan te sluiten bij hun eigen belevingswereld. Bovendien is het belangrijk om mensen uit de praktijk bij het onderwijs te betrekken [11]. Het doel hiervan is patiëntveiligheid uit te dragen: docenten dienen rolmodellen van de proactieve arts te zijn met groot risicobewustzijn, patiëntgericht verantwoordelijkheidsgevoel en oog voor professionele samenwerking. Daarnaast is het van belang om aspecten van patiëntveiligheid te integreren in andere onderwijsmomenten, zoals farmacotherapie, klinisch redeneren, samenwerken en klinische vaardigheidstraining, maar ook bij de introductie van bepaalde modules, zoals communicatie en patiëntveiligheid, omgang met technische apparatuur en patiëntveiligheid, samenwerking en patiëntveiligheid. Wanneer op die momenten sprekende voorbeelden worden genoemd om de relevantie van patiëntveiligheid aan te geven, wordt het voor studenten ineens veel tastbaarder en toepasbaar. Hoewel dit voor aios vooral geldt voor onderwijsmomenten in de praktijk, geldt dit natuurlijk ook voor het basiscurriculum waar patiëntveiligheid op meerdere momenten en op verschillende manieren aan bod kan komen.

\section{Voorbeelden van werkvormen}

In de basisopleiding is het doel het kennen en herkennen van risico's voor de patiëntveiligheid. Deze vaardigheid ontwikkelt zich in de vervolgopleiding naar het herkennen van risico's voor de patiëntveiligheid in de dagelijkse praktijk en toepassen van niet-klinische vaardigheden. Voor beide doelen zijn werkvormen beschikbaar [6]. Deze werkvormen lopen op in intensiteit en vereisen een veilige omgeving en professionele begeleiding van het proces. Voor het kennen en herkennen van risico's voor de patiëntveiligheid zijn dit onder andere:

- Het inbrengen van eigen voorbeelden, bijvoorbeeld van een moeilijke situatie in de samenwerking. Deze voorbeelden kunnen uitgewerkt worden en eventueel nagespeeld worden om vervolgens te analyseren.

- Observaties. Studenten en aios kunnen in de eigen praktijk observaties doen. Aan de hand van observatieschema's kan bijvoorbeeld gelet worden op: Wat viel op? Wat ging goed en wat kan beter? Ook kunnen studenten en aios foto's maken van patiëntonveilige situaties tijdens het werk om klassikaal te bespreken.

- Het gebruik van een rollenspel, dat vooraf op papier is uitgewerkt. Niet alle studenten of aios hoeven deel te nemen aan het rollenspel. Een aantal kan ook de rol van observator hebben. Ook kan een rollenspel met goed geïnstrueerde acteurs als patiënt of professional worden ingezet.

- Laten zien van video-opnamen van medische praktijksituaties. Studenten en aios kunnen naar patiëntveiligheidsaspecten zoeken, deze beoordelen en samen bespreken.

Voor het verder herkennen van risico's voor de patiëntveiligheid in de dagelijkse praktijk en het toepassen van niet-technische vaardigheden, zijn geavanceerdere werkvormen beschikbaar, die meer van de competentie van studenten of aios vragen. Deze werkvormen lichten we hierna verder toe:

- Medische simulatietraining is een steeds meer toegepaste trainings- en feedbackmethode, waarin deelnemers taken en processen oefenen onder realistische omstandigheden [6]. Deze ontwikkeling is gestart naar voorbeeld van cockpitsimulatietraining in de luchtvaart, eveneens een beroepsgroep waarin grote risico's en werken onder hoge druk samengaan, en tevens een plaats waar een kleine fout snel rampzalige gevolgen kan hebben. De voor de geneeskunde ontwikkelde geavanceerde oefenpoppen (patiëntensimulatoren) voorzien de zorgprofessionals van een gecomputeriseerde patiënt. Medische simulatie maakt het mogelijk individuen en teams net zo vaak scenario's en procedures te laten trainen, totdat 
deskundigheid op het gebied van zowel technische vaardigheden als vooral niet-technische vaardigheden verkregen wordt zonder risico voor patiënten. Belangrijk is dat de nadruk vooral op zelfreflectie van de deelnemers ligt. Simulatietraining is een ideaal platform voor betere begripsvorming tussen verschillende afdelingen en professies in de zorg, zoals artsen en verpleegkundigen. Het door de simulatiesessie ontstane wederzijdse begrip kan samenwerking in de toekomst verder verbeteren.

- Videoreflectieve methoden worden zowel in klassikale als in simulatietrainingen vaak gebruikt voor het evalueren en optimaliseren van complexe zorgprocessen. De methode 'Beelden aan Bed' van het Universitair Medisch Centrum Utrecht is in 2008 ontwikkeld als instrument voor kwaliteitsverbetering van multidisciplinaire zorgteams [12]. Tijdens een Beelden aan Bed traject vormen videobeelden uit de eigen dagelijkse beroepspraktijk van zorgprofessionals het uitgangspunt voor reflectie en verbetering. De hulpvraag van een zorgteam bepaalt op welke momenten er op de werkvloer gefilmd gaat worden. De focus kan bijvoorbeeld gericht zijn op het verbeteren van de overdracht van OK naar recovery. De nadruk van de reflectie ligt op het vlak van niet-technische vaardigheden, zoals het herkennen van risico's, communiceren en leiding geven, eventueel gecombineerd met klinische vaardigheden, bijvoorbeeld de reanimatieprocedure of de uitvoering van een zeldzame stuitbevalling.

- Verhalen van patiënten of collega's (storytelling) zijn een krachtig middel voor het bespreken van patiëntveiligheidsrisico's [13]. Openheid over een gemaakte fout is geen vanzelfsprekendheid. Het is moeilijk om een dergelijke ervaring te delen. Open zijn over fouten vergt moed, maar ook een omgeving die bereid is om onbevooroordeeld te luisteren. Openheid en onbevooroordeeld luisteren zijn nog lang niet overal gemeengoed zijn. Verhalen waarbij de knelpunten vanuit het perspectief van de patiënt of collega centraal staan, geven inzicht in problemen bij de samenwerking en communicatie tussen patiënten en zorgverleners. Verhalen blijven hangen en inleving in de realiteit van patiëntveiligheid versterkt, meer dan frameworks, accreditatieschema's en protocollen.

- Ondersteuning van het second victim en peer support, ofwel de aandacht voor en opvang van collega's die betrokken zijn bij een calamiteit. Wanneer een arts betrokken is bij een fout die de patiënt ernstige schade toebrengt, heeft dat ook een overweldigend effect op de arts. Schuld, schaamte en angst zijn geen ongebruikelijke reacties, maar artsen zijn vaak gewend die vóór zich te houden. Met peer support wordt beoogd competenties te ontwikkelen waarmee de arts om kan gaan met gemaakte fouten, waarbij in een veilige omgeving gereflecteerd wordt op gedrag, zorg en de samenwerking in een team. De kracht van de methode is dat bij snelle emotionele ontlading en begrip van collega's het traumatische effect afneemt en de openheid over fouten veel groter wordt. In de opleiding tot arts en medisch specialist en in het dagelijks werk is er nog maar weinig aandacht voor deze vorm van professioneel gedrag. Het Universitair Medisch Centrum Groningen werkt verder aan deze methode [14].

\section{Patiëntveiligheidsonderwijs in de praktijk}

Praktisch gezien zal, om het onderwijs rondom patiëntveiligheid goed te kunnen neerzetten, eerst op detailniveau in kaart moeten worden gebracht waar het onderwijs over patiëntveiligheid in de huidige curricula op dit moment aanwezig is, welk niveau dit onderwijs heeft en in hoeverre het overeenstemt met de opnieuw geformuleerde leerdoelen. Deze nieuwe leerdoelen moeten beoordeeld worden op haalbaarheid, zijn ze misschien te hoog of te laag gegrepen voor de opleiding? De docenten en specialisten die het onderwijs op het gebied van patiëntveiligheid verzorgen, zullen qua diepgang goed genoeg op de hoogte moeten zijn van patiëntveiligheid om dit in hun onderwijs te integreren. Uit voorgesprekken met docenten zal blijken of het nodig is om docenten hierin te scholen of dat zij al over voldoende kennis en kunde beschikken. Ook de opleiding zelf moet up-to-date gehouden worden. Het vakgebied patiëntveiligheid is sterk in ontwikkeling en biedt constant nieuwe inzichten die van belang zijn voor het onderwijs aan studenten en aios.

Bij het opzetten van patiëntveiligheidsonderwijs dient men daarnaast ook de organisatie, het proces, de technische middelen en de patiënt voor ogen te houden [3]. Daarmee bedoelen wij het systeem waarin patiëntveiligheidsonderwijs plaats moet vinden. Dit systeem speelt in alle fasen van integratie van onderwijs een rol. Zo kan de integratie van patiëntveiligheidsonderwijs niet van het ene op het andere moment worden gerealiseerd, omdat het nemen beleidsbesluiten veel tijd kost. Bovendien kunnen andere ontwikkelingen mogelijk (onbedoeld) tegengestelde werkingen hebben, zoals wet- en regelgeving met betrekking tot kortere werktijden en toenemende efficiëntie van de zorg, maar ook technologische of economische omstandigheden kunnen een rol spelen, waardoor integratie van patiëntveiligheidsonderwijs moeizaam verloopt. Onderwijs valt of staat met integratie in het systeem dat een leven lang leren nu eenmaal moet faciliteren. Om veerkrachtig nieuwe patiëntveiligheidsproblemen op te vangen, hebben artsen een scherp oog voor risico's nodig, plus vaardigheden in oorzakenanalyse en identificatie van passende oplossingen, waarbij de inbreng van collega's van meerdere disciplines meestal van groot belang is. Met een betere 


\section{Hier staat een advertentie.}

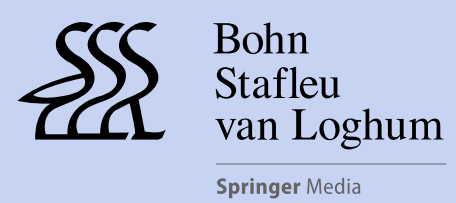

Houten 2016 


\section{Hier staat een advertentie.}

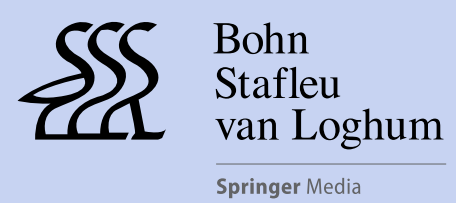

Houten 2016 
inbedding van patiëntveiligheidsonderwijs in curricula kan een generatie artsen worden opgeleid die een bewustere houding ten aanzien van patiëntveiligheid behoudt, temidden van alle uitdagingen die een constant veranderende, complexe werkomgeving met zich meebrengt.

Open Access This article is distributed under the terms of the Creative Commons Attribution 4.0 International License (http:// creativecommons.org/licenses/by/4.0/), which permits unrestricted use, distribution, and reproduction in any medium, provided you give appropriate credit to the original author(s) and the source, provide a link to the Creative Commons license, and indicate if changes were made.

\section{Literatuur}

1. Wagner $\mathrm{C}$, Wal $\mathrm{G}$ van der. Voor een goed begrip. Bevordering patiëntveiligheid vraagt om heldere definities. Med Contact (Bussum). 2005;60:1888-91.

2. Langelaan M, Bruijne MC de, Baines RJ. et al. Monitor Zorggerelateerde Schade 2011/2012: dossieronderzoek in Nederlandse ziekenhuizen. Amsterdam Utrecht: VUmc EMGO+/Nivel; 2013.

3. Schout BMA, Vries AH de, Koldewijn EL. et al. Rapport training in urology. 1e fase implementatie 2012-2013: 40-uren project. Nuenen: Stichting Opleiding Medici; 2013.

4. Bolk MHH. Borgen van leren rondom patiëntveiligheid in het medisch en verpleegkundig onderwijs. Houten: MBOOA; 2011.

5. Herwaarden CLA van, Laan RFJM, Leunissen RRM. Raamplan Artsopleiding. Utrecht: NFU; 2009.
6. Bruijne MC de, Bleeker F. Medisch teamwork. CRM in de gezondheidszorg, 1st. ed. Houten: Bohn Stafleu van Loghum; 2013.

7. Vries AH de, Luijk SJ van, Scherpbier AJ, et al. High acceptability of a newly developed urological practical skills training program. BMC Urol. 2015;15(1):93.

8. Luijk SJ van, Koster W. Disciplineoverstijgend onderwijs voor artsen in opleiding tot specialist. Programma 2011. Onderwijs- en opleidingsregio VU medisch centrum. band 2011. Amsterdam: PAOG cursus; 2013.

9. WHO Patient Safety. Curriculum guide for medical schools. Genève: World Health Organization; 2009.

10. CanMed's 2015 Framework. Beschikbaar via: http://www. royalcollege.ca/portal/page/portal/rc/canmeds. Geraadpleegd op 30 mei 2016.

11. Aron DC, Headrick LA. Education physicians prepared to improve care and safety is no accident: it requires a systematic approach. Qual Saf Health Care. 2002;11:168-73.

12. Vries B de. Videoreflectie helpt zorgprofessionals hun gezamenlijke praktijk te verbeteren. BPM Medica. 2014;7:7-11.

13. Leistikow IP, Buikema M, Drent R. et al. Dit nooit meer: artsen vertellen over hun incident. Utrecht: Kwaliteitsinstituut voor de Gezondheidszorg CBO; 2009.

14. Shapiro J, Galowitz P. Meer steun nodig voor arts bij medische fout. Ned Tijdschr Geneeskd. 2016;160:D181.

dr. Lisanne M. Verweij onderzoeker NIVEL

dr. Martine C. de Bruijne Universitair hoofddocent Patiëntveiligheid

prof. dr. Cordula Wagner directeur NIVEL en hoogleraar patiëntveiligheid 